ARTICLE

\title{
Indeterminate Film-thinking and Interpretation
}

\author{
JIMMY BILLINGHAM, University of Sussex
}

\begin{abstract}
I challenge David Bordwell's distinction between the act of comprehension and the process of interpretation in the construction of meaning in narrative film, drawing on Wolfgang Iser's concept of indeterminacy and Daniel Frampton's concept of filmthinking and the 'filmind' to demonstrate that in understanding narrative as a series of causally linked events the viewer segments and forms determinate relationships between events presented in the narrative. This activity can be facilitated by the thinking of the filmind by presenting events in their causal order, providing expositional information and by limiting possible causal combinations, such that a deviation from these practices of narrative articulation leads to an increased amount of indeterminacy between events, requiring more interpretative activity on the part of the viewer to connect them in cause and effect relationships, and in so doing 'completing' the narrative-thinking of the filmind.
\end{abstract}

\section{KEYWORDS}

Film narrative; indeterminacy; interpretation; understanding.

In his description of the construction of meaning in narrative film, David Bordwell distinguishes between the activity of comprehension and the process of interpretation, the difference being that 'the activity of comprehension constructs referential and explicit meanings, while the process of interpretation constructs implicit and symptomatic meanings' (Bordwell, 1989: 9). According to Bordwell, a viewer constructs these referential and explicit meanings in their understanding of narrative:

In comprehending a narrative film, the spectator seeks to grasp the filmic continuum as a set of events occurring in defined settings and unified by principles of temporality and causality. To understand a film's story is to grasp what happens and where, when, and why it happens.

(Bordwell 1985: 34)

Bordwell regards interpretation as a process that occurs independently of narrative comprehension and the construction of fabula (story). This is his point of departure for proceeding with a critical account of how interpretation forms the staple activity of much 'contemporary film theory': by this account the theorist acts as a critic, drawing out hidden and symptomatic meanings in accordance with conventional paradigms of interpretation (psychoanalysis being the dominant one in most contemporary film theory). It is this tendency that Bordwell and Noel Carroll critique in their edited collection of essays, Post-Theory: Reconstructing Film Studies (1996), in which 
Bordwell states that '[e]ver since the $1960 \mathrm{~s}$, interpretation has been central to academic film studies, and both theoretical and historical work have been subordinated to it' (Bordwell, 1996: 24). And Carroll shares this view of the 'conflation of film theory with interpretation,' believing that 'the major impediment to film theory in the present moment is the confusion of film theory with film interpretation. Many film scholars imagine that they are producing film theory when they are actually merely contriving interpretations of individual films' (Carroll, 1996: 42).

This process of interpretation is said to occur independently from the comprehension of narrative (grasping what happens, where, when and why) - hidden meanings are apparently located within these literal meanings. Bordwell seeks to sideline this process of interpretation as distinct from the viewer's act of comprehending narrative, critically evaluating this interpretative practice in Making Meaning: Interference and Rhetoric in the Interpretation of Cinema (1989): Carroll notes that, '[a]s has been pointed out by David Bordwell in Making Meaning, film theory is generally integrated into film studies as a template from which film scholars strike interpretations of individual films' (Carroll, 1996: 42). And as Perkins says of Bordwell's critical evaluation of contemporary film theory's interpretive practices in Making Meaning, '[i]ts most consistent and probably intended effect is to portray interpretation as a boringly repetitive impediment to our understanding of cinema' (Perkins, 1990: 3). I wish to contend this distinction between comprehension and interpretation and propose that understanding narrative as a series of causally linked events constructing the fabula, in Bordwell's terms - can involve an act of interpretation.

The literary theorist Wolfgang Iser proposes his theory of the Act of Reading (1978) in response to similar issues within literary theory and criticism that Bordwell responds to within film theory (or criticism, as Bordwell would properly describe it). Iser sought to counter the classical norm of interpretation, according to which 'interpretation consists in forcing the hidden meaning from a text' (Iser, 1978: 4). Iser instead looks at how meaning is produced in the act of reading, regarding meaning not as 'a definable entity but, if anything, [as] a dynamic happening' (22): a text has the potential for meaning that is realized in the act of reading. According to Iser, the literary text is indeterminate, and this indeterminacy stimulates the reader to produce a determinate, consistent meaning in the act of reading. This involves interpretation because the text is indeterminate to such an extent that various meanings are possible. So Iser, with his theory of reader-response, is concerned with how these interpretations are produced in the act of reading, rather than with these interpretations themselves. As he puts it,

One task of a theory of aesthetic response is to facilitate intersubjective discussion of individual interpretations. Clearly, such an intention is a reaction to the spreading dissatisfaction arising out of the fact that text interpretation has increasingly become an end in itself.

Though both Iser and Bordwell are responding to a similar situation in which 'text interpretation has increasingly become an end in itself,' they propose differing accounts of the role of interpretation in the production of a text's meaning.

According to Iser, the literary text is incomplete, being composed of multiple 
perspectives segmented within the text, which together make up the imaginary object of the text. Between these segmented perspectives lies 'a no man's land of indeterminacy' (Iser, 1989: 9) - a blank - and by reciprocally relating these segments, the viewer forms determinate relationships between them, filling the blank. This production of meaning involves the interaction of the reader in deciding how these blanks are to be filled, for '[i]t is quite impossible for the text itself to fill the blanks' (9). These indeterminate structures make possible a multitude of potential meanings: Iser states that 'each individual reader will fill the gaps in his own way' (Iser, 1974: 280 ), and that 'one text is potentially capable of several different realizations, and no one reading can ever exhaust the full potential' (280). I propose that a related indeterminacy can be found in film on the level of plot (an area, or 'perspective' as he refers to it, that Iser seems to pay least attention to), and that in the act of viewing, the viewer fills these gaps in constructing the story, or fabula,

A film differs from Iser's description of a literary text because a film is not made up of a series of perspectives, which in the context of the literary text Iser describes as 'those of the narrator, the characters, the plot, and the fictitious reader' (Iser, 1989: 35), although some of these different elements may be represented within a film. For example, a voice-over narrator may narrate parts of the story directly to the viewer, providing supplementary and explanatory information, as in Blade Runner (Ridley Scott, 1982), for example. Bordwell describes narration 'as a process, the activity of selecting, arranging, and rendering story material in order to achieve specific timebound effects on a perceiver' (Bordwell, 1985: xi). However he is resistant to the idea that this process of narration necessarily entails an extra-diegetic figure that narrates the story to the viewer: 'Even if no voice or body gets identified as a locus of narration, can we still speak of a narrator as being present in a film? In other words, must we go beyond the process of narration to locate an entity which is its source?' (62). He later states that 'to give every film a narrator or implied author is to indulge in an anthropomorphic fiction' (62).

Bordwell positions his own constructivist theory of narration in opposition to what he refers to as diegetic theories of narration, which regard narration as recounted by some kind of narrating entity. These diegetic theories, influenced by literary and linguistic theory, propose various narrating figures, such as Metz's concept of the 'grand imagier,' which he uses to describe the 'selecting and arranging' function of a filmic narrator 'situated somewhere behind the film, and representing the basis that makes the film possible' (Metz, 1973: 21). Sarah Kozloff, influenced by this Metzian model, refers to an 'image maker,' stating that 'image maker clearly captures the activity of the off-screen presence - making images - where 'making' is broad enough to encompass all the selecting, organising, shading, and even passive recording processes that go into the creation of a narrative sequence of images and sounds' (Kozloff, 1988: 44). Seymour Chatman locates a cinematic narrator, which he describes as

the transmitting agency, immanent to the film, which presents the images we see and the sounds we hear. It is not the filmmaker or production team but bears the same relation to those real people as does the narrator to the real author of a novel. Neither is it a voice-over that introduces the action, though that voice-over may be one its devices.

(Chatman, 1990: 211) 
Robert Burgoyne also identifies a narrator in film, referring to an 'impersonal narrator' that 'both creates or constructs the fictional world while at the same time referring to it as if it had an autonomous existence' (Burgoyne, 1990: 7). And Inez Hedges uses the term "arranger' for the controlling consciousness that must ultimately be held responsible for the selection and combination of the sounds and images of the film' (Hedges, 1991: 3).

Daniel Frampton, like Bordwell, is critical of that fact these narrating entities 'create anthropomorphised narration' (Frampton, 2006: 34), and in so doing posit some kind of external perspective on the film. In order to counter these shortcomings, Frampton proposes the idea of a 'filmind,' which derives from his idea of 'film as thinking,' both described in detail in his Filmosophy (2006):

Filmosophy is a study of film as thinking, and contains a theory of both filmbeing and film form. The 'filmind' is filmosophy's concept of film-being, the theoretical originator of the images and sounds we experience, and 'filmthinking' is its theory of film form, whereby an action of form is seen as the dramatic thinking of the filmind.

Daniel Frampton describes the filmind as a thinking-perspective which 'intends from a non-place or realm of perspective rather than a singular point of view. The filmind is not outside the film, it is the film. The film's perspective is the whole film' (Frampton, 2006: 86). Frampton describes two aspects of this intentional perspective: the filmind creates its world, such that it consists of recognisable features, however it simultaneously re-creates, or 'refigures,' this world in that within this created world the filmind is constantly making decisions, choosing what to show, and how to show it: the filmind is, as Frampton puts it, 'selector, chooser, [and] arranger' (83). This intention is manifest in the filmind's selection of certain images, which are shown in a particular fashion, depending on variables such as framing, colour, focusing, movement and edit shifts. The filmind 'both creates the object and necessarily thinks it in certain way' (90).

It is in this respect that the intention of the filmind as a thinking-being is manifest, and this intentional thinking occurs constantly, to the extent that there is no film-world apart from as it is thought by the thinking-filmind. The film-world (created and refigured by the filmind) and film-thinking are inseparable: the filmind 'both intends towards and 'is' the film-world' (90). As Frampton states, the filmind is 'a pure intentionality' (87) which 'never stops thinking' (84).

As I mentioned earlier, Iser locates indeterminacy between the various textual perspectives that make up the literary text. I contend that in narrative film there is an amount of indeterminacy within the single perspective of the filmind. Rather than experiencing the world of the text via the written, mediated perspectives within the literary text, the film-viewer experiences the world of the film directly as the filmind's perspective, so whereas in Iser's account these perspectives provide linguistic 'instructions' which 'stimulate mental images' (Iser, 1978: 36), the film(ind) itself thinks these mental images which are presented on screen to the viewer, directly as the filmind thinks. 
I propose that within this thinking perspective which thinks the whole of the filmworld, it is possible to locate an equivalent filmic position to Iser's conception of the implied reader: an implied viewer. Iser describes how 'the concept of the implied reader designates a network of response-inviting structures, which impel the reader to grasp the text' (34). This implied reader has two aspects: 'the reader's role as a textual structure, and the reader's role as a structured act' (35). The textual structure of the implied reader is a 'standpoint' from which the reader draws together all the textual perspectives that the text is composed of. The textual structure of the implied reader is not a perspective represented within the text but is 'the vantage point from which . . . [the reader] joins them together' (36). The perspective of the filmind has already partially taken up this position as an implied viewer, in that its image-thinking filters all other perspectives within the world of the film: as Frampton puts it, 'the filmind operates from a uniquely transubjective non-place, thinking for itself or a 'narrator' or a character, or whatever. The filmind handles all: views of the character and that character's point of view' (Frampton, 2006: 87).

Frampton emphasizes how '[f]ilm-thinking suggests, hints, gives us a vague notion of (perhaps 'particular') ideas. The filmind thus produces emotional ideas, feelings of thoughts, fragments of concepts - fruitfully vague in structure, intentionally blurry in meaning' (98). In viewing the film, the viewer's thinking engages with the filmthinking: as Frampton puts it, '[t]he filmgoer does not so much 'identify' with the film (or its characters) as 'join' it in the creation of a third thinking' (162). So the filmind has within it the potential for a 'third thinking,' created when the two thinking perspectives of the filmind and viewer merge, for the ' $[\mathrm{t}] \mathrm{he}$ filmind does not determine meanings, it determines actions of film-thinking by which we receive and create meanings' (101). These 'actions of film-thinking' stimulate the viewer to 'receive and create meanings,' and there is where Iser's definition of the 'structured act' of the implied reader comes into play. The structured act occurs when the actual reader - in their reading of the text - takes on, or 'realizes,' the role of the implied reader, joining the textual perspectives of the text by establishing determinate relationships between them. As Iser puts it, [t] extual structure and structured act are related in much the same way as intention and fulfillment' (Iser, 1978: 36). So in receiving and creating the meanings of the filmind's thinking, the viewer can be said to fulfill the intention of this film-thinking, resulting in the realized 'third thinking' of the implied viewer. My focus is on how, in understanding narrative, the viewer essentially 'completes,' or at least strives to complete, the narrative-film-thinking of the filmind, and how indeterminate features within this type of film-thinking stimulate the interpretive activity of the viewer in their understanding of narrative as a series of causally related events; this being 'one result of film-thinking, a certain type of thinking, one which lines-up plots and characters to tell a story' (113).

As I quoted earlier Bordwell states that '[i]n comprehending a narrative film, the spectator seeks to grasp the filmic continuum as a set of events occurring in defined settings and unified by principles of temporality and causality.' I want to show that this act of comprehension inevitably shades into interpretation as indeterminacy increases. In understanding the narrative of a film the viewer causally connects certain events, forming determinate relationships between them. What counts as an event and how they are causally related is not explicitly stated by the film but is indicated by the thinking of the filmind with varying degrees of determinacy - the viewer experiences a continuum of action, within which they must segment particular events and combine 
them in causal relationships. This activity may be facilitated by the thinking of the filmind, reducing the amount of indeterminacy between events, and it can also be frustrated by the thinking of the filmind, such that the viewer struggles to form determinate relationships between events. I will now outline some of the ways in which film-thinking can either increase or limit narrative indeterminacy.

In connecting two events in a causal relationship the viewer segments these events as causally related, establishing a determinate relationship between them. Various types of relationships can be formed between events, as Edward Branigan sets out in the following scale:

1 Elements are merely consecutive ('and'); their order is arbitrary or optional.

2 Elements are chronological ('then'); order is governed only by duration.

3 Elements appear together conventionally; order is set by familiar social or generic practices.

4 An element (the 'remote' cause) appears together with another element but only through the mediation of many other elements ('intervening' causes), the last of which is the immediate or proximate cause.

5 An element is necessary for the appearance of another (an 'enabling' cause).

6 An element is sufficient for the appearance of another (a 'direct' cause). If two or more elements are present, each of which is sufficient to cause a particular outcome, the effect is 'overdetermined.'

7 An element is both necessary and sufficient for the appearance of another (a 'unique' cause).

(Branigan, 1992: 26)

This scale of possible relationships demonstrates the spectrum of determinacy that exists between events, from an entirely indeterminate relationship, in which one event has no bearing on another - one in no way determines, or causes, the other - to a determinate relationship in which one event alone, and only this event, determines, or causes, another. This pattern of causal relationships between events is a feature of the classic Hollywood narrative, as described by Susan Hayward:

The beginning of the film puts in place an event that disrupts an apparently harmonious order (marriage, small town neighbourliness, etc.) which in turn sets in motion a chain of events that are causally linked. Cause and effect serve to move the narrative along. At the end the disorder is resolved and order once again in place.

(Hayward, 2006: 82)

This type of narrative tends to be articulated in such a way as to facilitate the viewer's inference of cause and effect relationships between events. One of the ways in which this is facilitated is by depicting events in their causal order, as is the case in a recent example of the classic Hollywood narrative, Sleepless in Seattle (Nora Ephron, 1993).

Sleepless in Seattle accords with the above schematic description of the classic Hollywood narrative: it opens with the funeral of Maggie, Sam's wife and Jonah's 
mother. Her death has disrupted their family unit, which leads to Sam seeking out a new wife for himself and mother for Jonah. He then gets together with Annie after various obstacles obstruct their meeting, restoring the family unit, at which point the film ends. Sleepless in Seattle depicts events in chronological order, presenting a causal event and its effect in consecutive order, such that as events arise in the narrative the viewer is able to relate them as effects of previous narrative events, which may then cause subsequent events. ${ }^{1}$ For example, Jonah reads a letter from Annie - addressed to Sam - suggesting that Sam meet her at the top of the Empire State Building on Valentine's day. This causes Jonah to go to New York in order to meet Annie himself, as his dad refuses to. This then causes Sam to go to New York to find Jonah, resulting in him meeting Annie at the Empire State building, at which point their relationship begins and the film closes. These events are shown in this order in the narrative, with cause followed by effect.

However a film may also present events as temporally disordered. This nonchronological arrangement of events may consist of a flashback which proceeds to enact the events that caused the situation in the 'present' (the point from which these events are being recalled), as is the case in Billy Wilder's Double Indemnity (1944). This use of flashback temporally positions the viewer, such that they are aware that events being enacted are prior to the point from which they are being narrated by the character of Walter Neff. This flashback eventually catches up with the 'present' point in time from which Neff is explaining the course of prior events, by which point the viewer has been shown the cause of Neff's situation. However in Alejandro Inarritu's 21 Grams (2003) there is no such voice-over temporally grounding the viewer and announcing some events as occurring prior to others, therefore leading to an increased amount of indeterminacy between events. The viewer is instead presented with a series of seemingly disparate events that do not appear to follow chronologically. The viewer initially struggles to segment and combine these events into determinate causal relationships because they remain too causally remote from each other, but as more events are shown, the viewer is able to form determinate cause and effect relationships between events, and in doing so order the events in time.

Another way in which a film facilitates a viewer's construction of cause and effect relationships between events is by providing expositional information which serves to explain how events are linked. This can be provided by a character expositing their thoughts in a voice-over narration, as in Blade Runner and Double Indemnity. Expositional information can also be revealed through dialogue between characters, and in a more subtle and ambiguous fashion through physical expression, revealing a character's inner thoughts and feelings. For example, in Sleepless in Seattle when Annie smiles when she first hears Sam on the radio; her smiling expressing either happiness, comic amusement, affection, relief etc., or various combinations of these. A more direct explicit expression of her feelings towards Sam takes place when Annie tells her friend Becky - after hearing him on the radio - that Sam 'sounds nice.' These expressions, and others like it, serve to enable the viewer to understand subsequent actions by Annie - such as her writing the letter to Sam - as motivated effects, caused

1 Although it is obviously not the case that all events relate to each other in a single causal chain: various causal chains intersect. Sleepless in Seattle depicts two distinct causal chains (in which Sam and Annie are the respective protagonists) which intersect at various key points, leading to a mutual resolution-effect: Sam and Annie get together as a couple. Branigan writes that '[s]uch a double causal structure is typical of the classical narrative film' (Branigan, 1992: 30). 
by her hearing Sam on the radio, such that the viewer links the two events in a determinate causal relationship.

The exposition of a character's thoughts and feelings can provide the viewer with information that facilitates their connection of future events as effects of previous events: in expressing their thoughts and feelings characters reveal their motivation for future actions. I contend that a film such as Sleepless in Seattle minimizes indeterminate relationships between events as they arise in the narrative by presenting events chronologically, providing expositional information, and also by limiting the possibility of competing causal relationships, for example there is no other event presented in the narrative that can have caused Jonah to go to New York, other than receiving the letter from Annie. I will now look at a film that contains relatively little expositional information, Michael Haneke's The Seventh Continent (1989), leaving open the cause of a significant and climactic event in the narrative. I will then look at a film which encourages the viewer to connect specific events in a certain causal sequence, before then undermining this with the revelation of new information.

Michael Haneke's Seventh Continent (1989) shows the routine life of a middle-class Austrian family, husband and wife Georg and Anna and their daughter Evi, over the course of one day, for three years in a row. The film is split into three parts, each corresponding to the different years. In part one the family is shown carrying out normal everyday duties and activities. This routine activity is punctuated by moments of emotional drama and suffering: Evi is struck across the face by her mother as punishment for feigning blindness at school; at work Anna hears a story of a young girl who wet herself at school because she was tormented by other children; and at the dinner table Anna's brother sobs uncontrollably, following the recent death of their mother. Part two, taking place a year later, depicts many of the same routine activities, some in shot-for-shot repetitions. And again, emotional drama and suffering also takes place amongst this monotonous activity: Georg's old boss returns to work to collect his things, evidently unhappy and solemn, and with apparent pathos Georg tells him he has moved his belongings. And later on the way home from work the family witness the aftermath of a crash, seeing a dead body lying under a sheet of tarpaulin in the driving rain. The final part revisits the family the following year. It soon becomes apparent that the family's routine is about to be disturbed. The first indication of this is Georg telling Anna that 'we must cancel the newspaper subscription'. The viewer then learns, through Georg's internal narration (interior monologue) of his letter to his parents, that he has resigned from his job and that 'we have decided to leave because there is nothing to keep us here apart from you.' They are later shown at the bank withdrawing all of their savings, informing the bank manager that they're emigrating to Australia. The family continue their preparations for leaving - Georg sells the car, and Anna calls Evi's school to excuse her absence, although only because of illness: she makes no mention of their apparent plans to emigrate. Further doubt is cast on the reliability of the their stated intention to emigrate when the viewer hears more of Georg's internal narration, telling his parents (and the viewer) that although they had their doubts they have decided to take Evi with them, partly because she has expressed in the past that she is not afraid to die. The next day they collectively set about systematically destroying all of their possessions and property, before finally committing suicide.

Although the viewer may doubt their intention to leave for Australia (why would Anna 
lie to Eva's school?), this act of destruction, although hinted at through the Georg's buying of tools and his letter to his parents, nonetheless is unexpected by the viewer. This is because Haneke hardly provides any exposition of what is going on in the minds of his characters, and so their motivations for carrying out such a radical act of self-destruction remain unclear to the viewer. Indeed it is a hallmark of Haneke's work that characters are closed off as to their motivations for carrying out certain acts Haneke denies the viewer access to their inner thoughts, leaving it to the viewer to come to their own conclusions regarding a causal explanation of actions. ${ }^{2}$

As observed by Roy Grundmann, '[r]adically delimited camera perspective and visual fragmentation deny access to characters. Scenes of morning routines are parsed into tight close-ups of feet climbing out of bed, hands reaching for towels, torsos moving from bedroom to bathroom to kitchen' (Grundmann, 2007). Haneke also denies the viewer access to characters through a lack of dialogue: the characters hardly converse with each other, and when they do there is little expression of feeling and emotion. The subjects of conversation tend to be quite mundane, belying the true emotional and psychological drama taking place. What expressions of emotion there are tend to erupt dramatically as if from nowhere. For example, over dinner Anna's brother, Alexander, complements his sister on the food, asking her what she put in the seasoning. Anna tells him, but as just as she finishes listing the ingredients Alexander begins to sob, and does so with increasing vigour for the next minute and a half as his sister comforts him, clutching him to her bosom. And in the second car wash scene Anna begins to cry, apparently without immediate provocation, again for a lengthy period and with increasing vigour. There are several instances during the film in which the viewer hears either Anna or Georg internally narrating a letter they have written to Georg's parents. These periods of internal narration serve to exposit, and therefore explain, much of what the viewer sees. For example, the viewer is able to understand Alexander's crying as an event caused by the death of of his - and Anna's mother because earlier in the film Anna writes - and therefore the viewer hears - that Alexander had to undergo treatment for the depression he suffered following his mother's death, making it highly likely that his crying, and external manifestation of depression, is related to - that is, caused by - the death of his mother (making Anna's maternal embrace of Alexander all the more poignant). In Branigan's terms, the death of Alexander's mother is regarded by the viewer as a 'direct' cause of his crying.

These instances of narrational exposition are some of the few examples of the viewer being told information that enables them to form determinate causal relationships between events, as opposed to merely being shown these events. This exposition supplies the viewer with information that is potentially able to give them access to characters' thoughts, and is therefore able to explain their actions by providing the viewer with a likely cause. This type of exposition provides a psychologisation of characters and is something that Haneke, on the whole, avoids. Indeed, the narration of these letters is one of the few instances of the viewer being told anything about characters' thoughts: Haneke's general modus operandi is to show things to the viewer rather than tell them with words, and so explaining. As he expresses in an interview accompanying the DVD release of one of the other films in the 'glaciation' trilogy,

2 For example in the other two films belonging to what is commonly referred to as Haneke's 'glaciation trilogy,' Benny's Video (1992) and 71 Fragments of a Chronology of Chance (1994), in a similar fashion to The Seventh Continent the reasons for Benny's and Max's respective acts of murder are unclear. 
Benny's Video (1992), 'You explain with words in a book, you can explain a lot. In films you have to show things. . . . You can make films where you only talk and explain things, but it's not very cinematic.'

There is relatively little verbal communication between characters, providing little psychological insight. And when they do communicate with each other there is little expression or explanation of feelings, as if characters struggle to express themselves accurately and honestly through language. The effect of this for the viewer is that there is little information revealed that would enable them to assign determinate causes to characters' actions. Because of Haneke's refusal to psychologise his characters, providing insight through verbal exposition, the cause of the final act of suicide is left indeterminate. There is no one event that the viewer can identify as a necessary and sufficient cause of the suicide. The viewer must therefore interpret the cause of this suicide, locating a causal element, or many contributing elements, in the events of the narrative if they are to understand why this event took place. I will now describe some of these potential causal factors and the interpretation involved in regarding them as such. The following could be conceived as causes by the viewer: experiencing the repetition of routine daily life, witnessing the aftermath of a fatal car accident, hearing about war on the radio, and seeing Australia advertised as a holiday destination on a billboard. Regarding these events as causal factors involves an interpretation that they have a certain effect on the minds of Anna and Georg, ultimately leading to the view that life is no longer worth living, which is then acted upon in the act of suicide. The effects are these causal factors could be interpreted by the viewer as follows: the routine of daily life may cause the feeling that life is monotonous and unchanging; the accident may cause the feeling that life is unpredictable and cruel, and that one is never in complete control; hearing news of war on the radio may cause the feeling that life involves too much suffering; and the advert of Australia may cause them to yearn for what may be an impossible dream, representing unrealizable change to them. Any one of these things individually or all of them combined may have caused their ultimate actions, but the lack of expositional psyhologisation prevents the viewer from determinately connecting these events as causes of their collective suicide. In order to arrive at some explanation of this act, the viewer must interpret one or multiple causes from the series of events depicted in the narrative, which involves an assumption that characters are made to feel or think a certain way by a certain event: this is an assumption because the narrative does not provide this information (the characters do not themselves state why, or when, they have taken the decision to commit suicide), so by interpreting in this fashion the viewer provides the information that the narrative does not.

Cameron Crowe's Vanilla Sky (2001), unlike The Seventh Continent, presents the viewer with a significant amount of expositional information, guiding their inference of cause and effect. Initially this is presented to the viewer through an interview between David, the protagonist, and a psychiatrist who the viewer learns is questioning him over the death of his girlfriend, Sofia. Events are enacted as David recounts his memories to his psychiatrist, recalling his memory of the cause and effect sequence of events that lead up to his incarceration. According to this version of events, David was involved in a car accident with - and caused by - his on/off girlfriend, Julia, just after meeting Sofia. David's face was badly disfigured and Sofia initially refuses to see him. But after restoring his initial features through cosmetic surgery, David and Sofia fall in love again. However David then begins to hallucinate 
that Sofia is in fact Julia and ends up strangling her. But this version of events is undermined when the character of 'Tech Support' intervenes, informing David, and the viewer, that all the events following Sofia's rejection of David after his disfiguring accident are part of a lucid dream. This forces the viewer to re-evaluate their construction of cause and effect relationships between events, sorting the real events from the dreamt events: according to this 'lucid dream' scenario presented by the character of Tech Support, David did not commit murder, leading him to be arrested, as the narrative previously suggested - this murder was an effect of David's subconscious, turning his dream 'into a nightmare.' If this scenario presented by Tech Support is correct, then the interview sequence in which David is being question by a psychiatrist, recovering memories of David's past, presents an unreliable perspective on events, supplanted by the apparently authoritative perspective of Tech Support. However other causal relationships between events are possible, which would suggest that Tech Support is an unreliable narrator of events. For example, it is possible that David fell into a coma following a crash that is shown towards the beginning of the film, and that everything after this is dreamt by David during the coma. Each of these interpretations appears equally valid to the viewer, and each one involves segmenting 'key' events as proof of this interpretation and rejecting others that do not fit this interpretation as anomalous, for example the voice of Sofia saying 'open your eyes' at the very end of the film can support the theory that David fell into coma following his accident - this would explain why Sofia is there when he awakes. What is indeterminate is whether events are the effects of David's actions, or of the lucid dream that he signed up for: the lines between dreams and reality are indeterminate. Many of David Lynch's film also play on film's ability to depict dreams and reality with equal veracity, to the extent that it is not clear where the boundaries are. Many of Lynch's films (Lost Highway (1997), Mulholland Drive (2001) and Inland Empire (2006), in particular) contain large amounts of indeterminacy, as characters seem to split and merge, and transcend boundaries between dreams and reality, and between filmic worlds and real worlds. The apparent permeability of such boundaries in these films makes it difficult for the viewer to get a real grasp of how events are to be related to each other, leaving an even freer play for interpretation to establish connections between apparently unconnected events.

Bordwell acknowledges the indeterminacy of Lynch films, describing how '[c]ompletely indeterminate movies are rare in American cinema, . . . perhaps only David Lynch currently makes them' (Bordwell, 2006: 82), and describes how the indeterminacy of such 'art cinema' stimulates the viewer to engage in an activity of interpretation in response to this ambiguity: '[T]he art film solicits not only denotative comprehension but connotative reading, a higher level interpretation' (Bordwell, 1985: 212). However, as I mentioned earlier, he separates this activity from the comprehension of what he takes to be referential and explicit meaning. But I believe that indeterminacy is an inherent feature of film, and that an amount of interpretation figures in the viewing process, depending on the level of this indeterminacy. Indeterminacy is an inherent feature of film because the viewer must supply the causal connection between events - the thinking of the filmind may encourage the viewer to make these connections: as Frampton describes, '[ $t$ ]he filmind may be seen to think "causally"' (usually through editing), but there is no one particular sequence of images that denotes cause' (Frampton, 2006: 97). Film narrative is indeterminate because the segmentation of causally related events is implicit within the film to varying degrees (as I have shown). Understanding the film's story, or fabula, as a series of causally 
related events (the comprehension of 'referential meaning,' according to Bordwell (Bordwell, 1989: 8) will involve interpretation when the relationship between events, and the related issue of what counts as an event, is sufficiently indeterminate (as in The Seventh Continent and Vanilla Sky, for example). In this instance comprehension cannot be easily distinguished from interpretation, demonstrating that they are perhaps more appropriately regarded as both being on a continuum of viewer activity, therefore Bordwell's distinction between comprehension and interpretation as two distinct acts in the viewing process is untenable. However what I intend is not that comprehension may involve interpretation as it is described by Bordwell (constructing implicit and symptomatic meanings, 'spoken' by the film), but that constructing fabula involves more complex acts of understanding that are more appropriately labeled and described as 'interpretative acts,' a definition that Bordwell's conception of comprehension (as distinguished from the other acts of interpretation that he describes) seems to be trying to avoid.

So, to return to this idea of the filmind, in the act of viewing, the viewer strives to 'complete' the thinking of the filmind by receiving and creating the meaning of its film-thinking. In the context of narrative, or narrative film-thinking, the filmind thinks certain actions and happenings, and the viewer strives to complete this narrativethinking by segmenting this flow of events into cause and effect relationships. The filmind, as a 'guiding "attitude" and ... "agency"' (Frampton, 2006: 83), may either limit the amount of indeterminacy, aiding the viewer's completion of narrative-filmthinking, for example (as I discussed above), suggesting causality through editing, offering exposition, and limiting causal relationships. Or the filmind may increase the amount of indeterminacy by deviating from any one or all of these techniques, resulting in more interpretive activity being required by the viewer in order to complete the film-thinking. The more indeterminacy there is, the harder it is for the viewer to complete this film-thinking; and the more indeterminate the film-thinking, the less clear its intention. But as I hope I have been able to demonstrate, this activity of interpretation is a necessary part of the act of viewing and should therefore not be regarded and rejected as some kind of ad hoc critical practice, for as Richard Murphy suggests, "the kind of indeterminacy which creates "ambiguity" and so requires "connotative" and "higher-level interpretation" is always present in texts, and not just in the specialized domain of the art cinema' (Murphy, 2004: 135).

\section{References}

Bordwell, D. (1985) Narration and the Fiction Film. London: Routledge

Bordwell, D. (1989) Making Meaning: Interference and Rhetoric in the Interpretation of Cinema. Cambridge, Massachusetts: Harvard University Press

Bordwell, D. (1996) Contemporary Film Studies and the Vicissitudes of Grand Theory. In: Bordwell, D. and Carroll, N., eds. Post-Theory: Reconstructing Film Studies. Wisconsin: University of Wisconsin Press

Bordwell, D. (2006) The Way Hollywood Tells It: Story and Style in Modern Movies. 
Berkeley, Los Angeles, London: University of California Press

Branigan, E. (1992) Narrative Comprehension and Film. London and New York: Routledge

Burgoyne, R. (1990) The Cinematic Narrator: The Logic and Pragmatics of Impersonal Narration. Journal of Film and Video, vol. 42, no. 1

Carroll, N. (1996) Prospects for Film Theory: A Personal Assessment. In: Bordwell, D. and Carroll, N., eds. Post-Theory: Reconstructing Film Studies. Wisconsin: University of Wisconsin Press

Chatman, S. (1978) Story and Discourse: Narrative Structure in Fiction and Film. Ithaca and London: Cornell University Press

Chatman, S. (1990). Coming to Terms: The Rhetoric of Narrative in Fiction and Film. Ithaca and London: Cornell University Press

Frampton, D. (2006) Filmosophy. London and New York: Wallflower Press

Grundmann, R. (2007) Michael Haneke's Cinema of Glaciation. Cineaste, vol. 32, no 2: 6-15. Gale Cengage Shakespeare Collection Periodicals, $10^{\text {th }}$ August 2008 $<$ http://shakespeare.galegroup.com.ezproxy.sussex.ac.uk/shax/>

Hayward, S. (2006) Cinema Studies: The Key Concepts. London and New York: Routledge

Hedges, I. (1991) Breaking the Frame: Film Language and the Experience of Limits. Bloomington and Indianapolis: Indiana University Press

Iser, W. (1974) The Implied Reader. Maryland: John Hopkins University Press

Iser, W. (1978) The Act of Reading: A Theory of Aesthetic Response. Baltimore and London: John Hopkins University Press

Iser, W. (1989) Prospecting. Baltimore and London: John Hopkins University Press

Kozloff, S. (1988) Invisible Storytellers: Voice-Over Narration in American Fiction Film. Berkeley / Los Angeles / London: University of California Press

Metz, C. (1973) Film Language: A Semiotics of the Cinema. New York: Oxford University Press

Murphy, R. (2004) The act of viewing: Iser, Bordwell and the 'Post-Theory' debates in contemporary film studies. Comparative Critical Studies $1(2 / 04)$

Perkins, V. F. (1990). Must We Say What They Mean?: Film Criticism and Interpretation. Movie, Vol. 34, Part 5

Wilson, G. (1997) 'Le Grand Imagier Steps Out: The Primitive Basis of Film 
Narration. In: Carroll, N. and Choi, J., eds. Philosophy of Film and Motion Pictures. Malden, Oxford, Victoria: Blackwell Publishing, 2005

\section{Filmography}

Benny's Video (1992). Directed by Michael Haneke, Austria/Switzerland, Tartan Video.

Blade Runner (1982). Directed by Ridley Scottt, USA, Warner Bros.

Double Indemnity (1944). Directed by Billy Wilder, USA, Paramount.

Inland Empire (2006). Directed by David Lynch, USA/Poland, StudioCanal.

Lost Highway (1997). Directed by David Lynch, USA, October Films.

Mulholland Drive (2001). Directed by David Lynch, USA/France, Universal.

The Seventh Continent (1989). Directed by Michael Haneke, Austria, Tartan Video.

Sleepless in Seattle (1992). Directed by Nora Ephron, USA, TriStar.

Vanilla Sky (2001). Directed by Cameron Crowe, USA, Paramount.

21 Grams (2003). Directed by Alejandro Inarritu, USA, Focus Features.

71 Fragments of a Chronology of Chance (1994). Directed by Michael Haneke, Austria, Tartan Video. 